\title{
Establishing a sex offender treatment programme within a prison
}

\author{
C. Jones
}

In 1991 the Prison Service began to develop a programme of treatment for sex offenders in custody. HMP Risley was the first establishment to successtully establish and run the 'Core Treatment Programme'. This paper examines some of the lssues involved in selting up such a programme, which was destoned to be implemented by relattvely inexperienced staff.

In June 1991 Kenneth Baker, the then Home Secretary, announced a new strategy for the treatment of sex offenders in custody (Prison Service, 1991). It came at a time of increasing public concern about sex offending, growing support for the concept of treatment for sex offending and a recent Criminal Justice Act which emphasised the role of rehabilitation during custodial sentences. The number of sex offenders in prison was rising (Prison Reform Trust, 1990) and the need for treatment was increasingly recognised (Severn, 1991).

Sixty-three prison establishments already provided some form of sex offender treatment, but these initiatives had been uncoordinated, with no common theoretical framework, and were often reliant on the enthusiasm and commitment of particular individuals. There had been no overall strategy for evaluation of the programmes, and selection of prisoners to recetve treatment was haphazard.

At the beginning of 1991 the director of Inmate Programmes held a seminar at which the strategy for treatment was determined. All prison establishments which had more than 50 inmates serving sentences for sexual offending were offered the chance to participate, whether or not they had previously provided such treatment.

Risley is a prison service establishment near Warrington in Cheshire, which for many years had been a remand centre. It had recently been redesignated as a multi-purpose prison, part of which was a Category $C$ training prison, and a new governor had been appointed. A significant programme of new building had commenced, which was to include a 'vulnerable prisoner unit' (VPU) as recommended by the Woolf Report (HMSO, 1991) to replace Rule 43 accommoda- tion. As a result, HMP Risley combined a desire for change and innovation with specific accommodation for a large number of vulnerable prisoners', virtually all of whom would be sex offenders.

\section{The programme}

The sex offender treatment programme devised by the directorate of Inmate Programmes was to combine assessment, treatment, review and longterm evaluation (Thornton \& Hogue, 1993). At first, prisoners serving sentences of more than four years were targeted, since they were subject to sentence planning procedures under the Criminal Justice Act, but other inmates considered to be 'high risk' could also be included.

A detailed and comprehenstve assessment package was planned, to be provided at four prisons which were identified as having sufficient expertise and resources. The Prison Psychology Service was responsible for coordinating and implementing the assessment package. Following this period of assessment, prisoners were to recetve a 'Core Treatment Programme', and where particular needs were identified various aspects of an 'Extended Treatment Programme' would also be provided.

The Core Treatment Programme was a responsibility-based strategy, and consisted of two components, the cognitive development and the risk awareness modules. Theoretically it was based on the cognitive-behavioural model of group therapy for sexual offenders, which has largely been developed in North America (Salter, 1988; Morrison et al, 1994). The programme was designed to run for $\mathbf{3 0}$ sessions of two hours each. and each session was tightly specified and defined so that it could be implemented consistently by relatively inexperienced staff.

The Extended Treatment Programme was a resource building strategy, consisting of a number of independent modules, one or more of which might be required in individual cases. These included stress and anger management, social 
Table 1. Initial training programme

- Introduction to counselling skills

- Models of offending

- Models of treatment

- The effects on victims

- Working in groups

skills training, alcohol awareness and deviant arousal reconditioning techniques. Following treatment, a reassessment, similar to the initial assessment, would be performed, necessitating a transfer back to one of the central establishments. The programme recognised the importance of on-going support once the treatment programme was completed, and eventual review and evaluation of the outcome of the treatment programmes, but these were not specified in detail during the initial stages.

Unfortunately, neither the pre-treatment assessment nor the post-treatment evaluation packages were developed at the same time as the core programme. Individual institutions were therefore left to run the core programme as a pilot scheme, without the benefit of any formal assessments.

\section{Setting up at Risley}

A steering group was set up at HMP Risley consisting of a governor Grade 4, the principal officers and senior officer from the VPU, the senior probation officer, and a senior registrar from the local Forensic Psychiatry Service. At this point there were no psychologists employed at Risley, but shortly before the programme began two members of the Prison Psychology Service joined this group.

All prison officers and certain other groups of staff working at Risley were offered the opportunity to take part in the programme, and approximately 20 members of staff replied. A programme of training was organised by the senior registrar, which covered some basic aspects of working with sex offenders, and of group therapy skills.

An initial full day workshop was followed by five two-hour sessions comprising of a talk from a variety of visiting speakers (See Table 1) and a 30minute group session facilitated by the senior registrar, in which staff were encouraged to discuss their feelings about working with this group of offenders and to develop a degree of mutual support and group cohesion.

Following the basic training, 12 members of staff (nine prison officers, two probation officers and a member of the Education Department) were selected to form the initial group of therapists, or 'tutors' as they became known. Six of the tutors were male, and six female.
A series of national training seminars were run by the Prison Service, with six places allocated to each establishment. Five tutors plus one of the Steering Group members attended two one-week workshops, and on their return further local training was arranged for them to pass on what they had learnt to the rest of the group, with additional training from the Psychology Department.

At this stage of development the full assessment and selection programme had not been established, and it was decided to run a pilot group at Risley with prisoners selected locally from the current prison population. Probation officers and staff of the VPU were asked to identify possible participants, and of these 15 prisoners who were likely to remain at Risley long enough to complete the group, appeared motivated to address their offending behaviour, and fell into a 'high risk' group were interviewed by two of the tutors. Eight prisoners were selected as suitable for the group, and seven of them ultimately attended and completed the treatment programme. No sessions were missed by any of the group members.

\section{The pilot group}

It was decided that, although the programme would ideally be run by a small number of tutors. for the pilot programme all 12 of the tutors would be involved, in order to give them some experience in group working. A rota was devised which enabled some continuity between sessions to be provided. Time was provided before each session for preparation, and afterwards for discussion by the tutors alone and debriefing by a member of the management team. Each session was recorded in some detail in a log book, which tutors of future sessions could refer back to, and the debriefing sessions were also recorded. For most sessions a male and a female tutor were present, but on a small number of occasions this was not possible.

Each establishment running the core programme was given some discretion as to the arrangements for running the group. At Risley it was decided to run four sessions each week, and to complete the programme over a ten week period with a one week break in the middle. Four additional sessions were included to allow completion of topics which overran their allotted time. Each week a 'programme meeting' was held to ensure the arrangements ran smoothly, and the tutors met to discuss issues arising from the sessions. Confidential staff support from the Psychology Department was also arranged, with a formal staff support session on a weekly basis and informal arrangements as well. 
Although a number of practical problems were encountered the programme ran successfully, and a number of teething problems were successfully overcome despite the arrival of the programme specifications only shortly before the first session. Once the programme was completed a detailed evaluation was carried out. Questionnaires were completed by all the group members, eleven of the twelve tutors, and by all members of the Steering Group, to identify any problems or difficulties. A series of seminars was arranged covering all aspects of the treatment programme, to which everyone involved in the programme was invited.

As a result of the evaluation exercise a detailed critique of the programme was written, which made a number of suggestions for future programmes. A number of areas were identified in which tutors felt further training was required, and the need for continuing work and follow-up with the group members was emphasised. Formal staff support arrangements were seen as essential, with the involvement of outside agencies desirable.

Staff working on the VPU in particular reported that they had gained more trust from the prisoners, and had a greater rapport and understanding of them, to the benefit of their work outside the group itself. Overall the comments from all involved were favourable, and the pilot of the Core Programme was judged to have been successful. A second programme was subsequently run, incorporating some of the suggestions made.

The programme has continued to evolve, and ten groups have now been run at Risley, with as many as three running concurrently. Despite promotions and staff turnover, the majority of tutors have remained with the programme and additional tutors have been recruited.

\section{Conclusions}

Within a 12-month period, HMP Risley progressed from having no experience of therapeutic work with sex offenders to becoming the first prison establishment in the country successfully to establish and run the Core Treatment Programme. A keen and enthusiastic staff group was established, which implemented a high quality treatment programme. The development as a whole contributed significantly to the changing philosophy and increasing emphasis on rehabilitation within the establishment.
The programme within the wider prison service has now developed substantially, with the continuing development of pre-treatment assessment and the Extended Programme modules. This is particularly significant at a time when it seems increasingly unlikely that many sex offenders will receive hospital treatment.

The implementation of the programme demonstrated that a carefully designed and tightly specified programme can be run successfully by inexperienced therapists with relatively little training, so long as adequate supervision and support is provided. This has significant implications for the provision of sex offender treatment programmes, both within institutions and in the community, as the need for such programmes is increasingly recognised. More generally the provision of the Sex Offender Treatment Programme by the Prison Service deserves widespread encouragement, both as an example of therapeutic rather than custodial care, and as a provision of effective treatment for an often overlooked or underfunded group of patients.

\section{Acknowledgements}

I am grateful to Mrs G. Johnson, Senior Psychologist and Mr G. Hutchinson, Governor 4 at HMP Risley, the Treatment Manager and Programme Manager respectively, for their helpful comments.

\section{References}

HMSO (1991) Prison Disturbances. April 1990. Report of an Inquity by the Rt. Hon. Lord Justice Woolf and His Honour Judge Stephen Tumim. Cm. 1456. London: HMSO.

MORRISON, T., EROOGA, M. \& BECKETT, R. C. (1994) Sexual Offending Against Children. London: Routledge.

PRISON REFORM TRUST (1990) Sex Offenders in Prison. London: Prison Reform Trust.

PRISON SERVICE (1991) Treatment Programmes for Sex Offenders in Custody: A Strategy. London: HM Prison Service.

SALTER, A. (1988) Assessment and Treatment of Child Sex Offenders and Victims. Newbury Park: Sage.

SEVERN, P. (1991) Treating Sex Offenders in Prison. Joumal of Forensic Psychiatry. 2. 8-9.

THORNTON, D. \& HogUE, T. (1993) The large-scale provisions of programmes for imprisoned sex offenders: issues. dilemmas and progress. Criminal Behaviour and Mental Health, 3, 371-380.

C. Jones, Consultant Forensic Psychiatrist, North Wales Forensic Psychiatric Service, Unit 2, Clwydian House, Wrexham Technology Park, Wrexham, Clwyd LL13 TYP 